\title{
A fully coupled thermo-mechanical numerical modelling of the refill friction stir spot welding process in Alclad 7075-T6 aluminium alloy sheets
}

\author{
Andrzej Kubit ${ }^{1}$ (D) Tomasz Trzepiecinski²
}

Received: 23 March 2020 / Revised: 7 July 2020 / Accepted: 18 September 2020

(c) The Author(s) 2020

\begin{abstract}
Refill friction stir spot welding (RFSSW) is a solid state joining technology that has the potential to replace processes such as the open-air fusion bonding technique and rivet technology in aerospace applications. Selection of proper RFSSW parameters is a crucial task which is important to ensure the mechanical strength of the joint. The aim of this paper is to undertake numerical modelling of the RFSSW process to understand the physics of the welding process, which involves large deformations, complex contact conditions and steep temperature gradients. Three-dimensional fully coupled thermomechanical models of RFSSW joints between Alclad 7075-T6 aluminium alloy sheets have been built in the finite-elementbased program Simufact Forming. The simulation results included the temperature distribution and the stress and strain distributions in the overlap joint. The results of numerical computations have been compared with experimental ones. The numerical model was able to predict the mechanics of material flow during the joining of sheets of Alclad aluminium alloys using RFSSW. The predictions of the temperature gradient in the weld zone were in good agreement with the temperature measured experimentally. The numerical models that have been built are capable of simulating RFSSW to reduce the number of experiments required to set optimal welding parameters.
\end{abstract}

Keywords Alclad $\cdot$ Aluminium alloy $\cdot$ Mechanical engineering $\cdot$ Friction stir welding $\cdot$ FSSW

\section{Introduction}

Refill friction stir spot welding (RFSSW) is a solid-state joining technology which was developed in Germany in 2002 by GKSS-GmbH [1] as a variety of conventional friction stir spot welding (FSSW). In RFSSW technology, the rotational tool consists of an external stationary holder and rotary elements (pin and sleeve) designed to plasticise the material to be joined using friction. The construction of the tool allows independent vertical movement of the pin and sleeve. This allows the production of spot welds without an exit hole. The basic advantage of RFSSW is to replace

Tomasz Trzepiecinski tomtrz@prz.edu.pl

1 Department of Manufacturing and Production Engineering, Rzeszow University of Technology, Al. Powst. Warszawy 8, 35-959 Rzeszow, Poland

2 Department of Materials Forming and Processing, Rzeszow University of Technology, Al. Powst. Warszawy 8, 35-959 Rzeszow, Poland mass-adding fastening processes, such as screwing or riveting. So, RFSSW has great potential in the automotive, shipbuilding and aerospace industries. Moreover, this technology can join dissimilar materials which are difficult to join using fusion welding due to different thermal expansion coefficients and melting points.

An understanding of the physical and mechanical aspects of material flow in RFSSW could help to set optimal welding parameters which improve weld strength. A literature review of existing published research on the RFSSW topic revealed that most research was focused on experimental analysis of this process.

Due to the numerical character of the investigations presented in this paper, the review of research done by other authors is limited to computational investigations. Yang et al. [2] studied the numerical model of the plunge stage in the RFSSW of aluminium alloy established using smoothed particle hydrodynamics (SPH). The material flow patterns and velocity of material flow were investigated with the elastic-plastic deformation model. This paper only presents the possible applications of the SPH method in simulating 
RFSSW. No quantitative results and experimental validation have been presented. Muci-Küchler et al. [3] analysed a thermo-mechanical finite-element (FE) model of the plunge phase of RFSSW. The finite-element (FE)-based model has been developed in Abaqus/Explicit. The predicted temperature distribution in the weld zone shows good agreement with experimental studies. The results of simulation of material flow during FSSW of 6161 aluminium alloy sheets were presented by Cao et al. [4]. They used the Abaqus program with the coupled Eulerian-Lagrangian (CEL) formulation taking into account the dependence of stress on temperature, strain and strain rate. The authors analysed the effect of the process parameters on the forming of the hook defect and onion structure near the sleeve periphery. FE simulations designed to evaluate how the FSSW process parameters affect the temperature distribution in the welding region are presented in a paper by D'Urso and Giardini [5]. A 2D numerical model was experimentally validated showing a good capacity to predict the joint shear resistance and the maximum temperature in the welding zone. D'Urso et al. [6] made numerical studies of the temperature distribution and welding force as a function of the welding parameters. A 3D FE model of welding AA6060 T6 aluminium alloy sheets has been built in the Deform program considering a rigid-plastic material model. Malik et al. [7] developed a three-dimensional FE-based model of FSSW using the commercial Deform/Implicit code to select appropriate welding parameters to fill an exit hole in the weld. According to the conclusions provided, the process parameters obtained have the potential to reduce the number of experiments. A finiteelement model (FEM) coupled with the Arbitrary Lagrangian-Eulerian (ALE) method based on ABAQUS/Explicit software established by Yang et al. [8] was able to analyse the probeless FSSW process of 2198-T8 aluminium alloy. The Johnson-Cook equation was used to describe the flow stress and its dependence on temperature, plastic strain and strain rate.

A computational fluid dynamic technique is also widely used in simulations of the temperature distribution during the FSSW process. A 3D CFD model created in Fluent code allows one to simulate the control of the temperature of a friction welding tool during the joining process [9]. The tool temperature in the model was optimised to reduce the axial force of the tool. Atharifar et al. [10] applied the CFD technique to the simulation of heat transfer and material flow in the friction stir welding of AA6061 aluminium alloy. The temperature-dependent material properties and the stick/ slip condition have been assumed in the numerical model. Recent developments and applications of CFD simulation for the analysis of friction stir welding have been presented by Chen et al. [11].

Despite the many advantages of RFSSW technology over traditional riveting, which include the absence of an exit hole, no filler material being needed, no porosity and spatter being generated, easy automation, the RFSSW technology is not yet fully understood. The appropriate selection of RFSSW parameters (duration of welding, tool rotational speed, tool plunge depth) is crucial in assuring the proper strength of the joint $[12,13]$. The welding parameters are sensitive to many external conditions, like the grade of materials used, material thicknesses, material cladding, etc. Although many scientific publications dealing with this subject are already available, the guidelines determining the optimal RFSSW parameters for thin-walled aluminium alloy structures have not yet been clearly defined [14-16].

In the last decade, RFSSW technology has shown great potential for use in the joining of aluminium alloys used in the construction of aircraft structures $[17,18]$. The aim of most research was to determine the optimal welding parameters which allow one to reach the maximum load capacity of the joint in connection with the minimisation of possible weld defects. Previous studies have mainly focused on time consuming experimental testing of the effect of process conditions on the load capacity of joints and the macrostructure of friction spot welds $[19,20]$. Although, numerical modelling of the FSSW process is commonly used, numerical analysis of RFSSW is limited in the literature due to the more complex physico-mechanical phenomena in the weld zone and more complex kinematics of tool movement. The SPH-based numerical computations of the RFSSW process carried out by Yang et al. [2] concern only the plunge stage. Moreover, the correctness of the numerical model is difficult to verify, because the only properties of materials that the authors provided were the values of Poisson's ratio and Young's modulus. A fully coupled thermo-mechanical finite-element model developed by Muci-Küchler et al. [3] is also limited to the plunge phase. In this paper, a 2D axisymmetric fully coupled thermo-mechanical model of RFSSW of Alclad 7075-T6 aluminium alloy sheets has been built to predict the material flow and temperature distribution in the weld region over all phases of the RFSSW process, i.e. touchdown and preheating, plunging, refilling and retreating. Temperature and strain rate dependent material models of sheets and clad have been assumed. The results of numerical computations have been compared with experimental ones. Although the FSSW process has been widely studied in the literature, according to the best of the authors' knowledge, there is no numerical investigation of RFSSW deals with the analysis of material flow behaviour. 

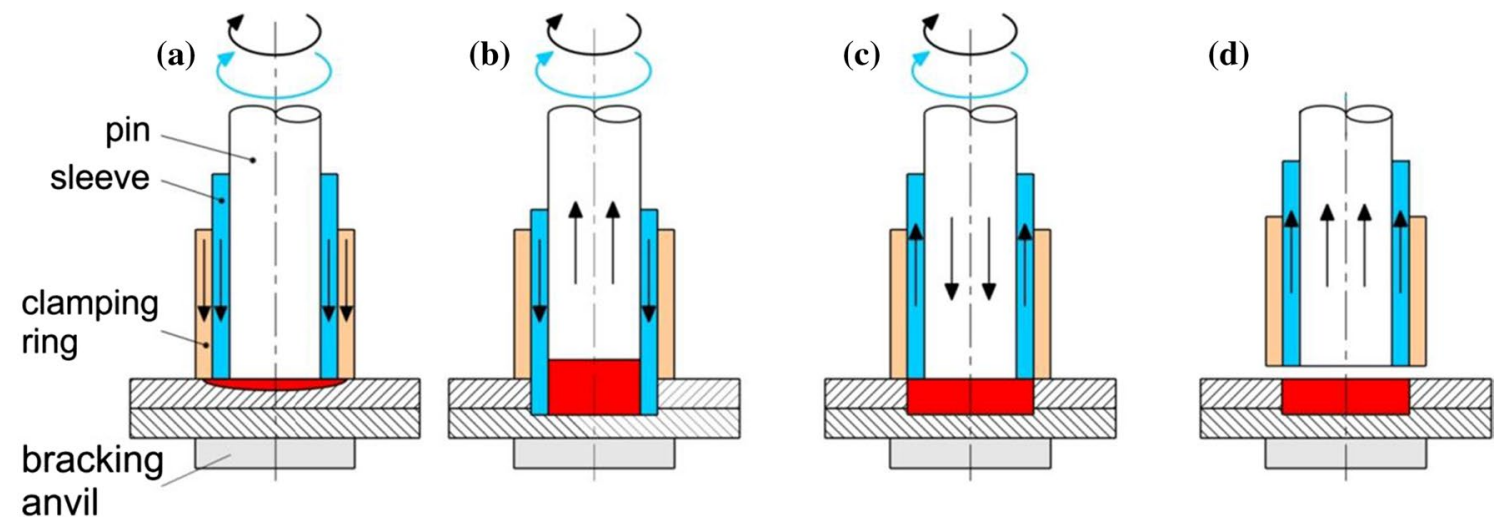

Fig. 1 Stages of the RFSSW process: touchdown and preheating (a), plunging (b), refilling (c), and retreating (d)

\section{Experimental investigation}

\subsection{Material}

RFSSW joints were made in $0.8 \mathrm{~mm}$-thick and $1.6 \mathrm{~mm}$-thick Alclad 7075-T6 aluminium alloy sheets. This metal alloy is a kind of non-weldable lightweight material and is characterised by high mechanical strength, comparable to that of structural steel, and a very high fatigue resistance. The 7075-T6 is a precipitation-hardened $\mathrm{Al}-\mathrm{Zn}-\mathrm{Mg}-(\mathrm{Cu})$ alloy that has been extensively used for highly loaded constructional elements in aircraft structural components. Alclad is a duplex material made by cladding an aluminum alloy core with surface layers of pure aluminum.

The mechanical parameters of the sheets tested have been determined by uniaxial tensile tests using a Z100 testing machine (Zwick/Roell, Ulm, Germany) according to the EN ISO 6892-1:2016 [21]. Three samples were tested and the average values of basic mechanical parameters were determined.

\subsection{Welding procedure}

The aim of the experimental tests was to obtain experimental results (temperature distribution and material flow behaviour) to validate the results of FE-based numerical computations. The experimental investigations of the RFSSW process were conducted using an RPS100 spot welder by Harms \& Wende GmbH \& Co KG (Hamburg, Germany). The welding tool used was equipped with a welder and consists of three independent elements (Fig. 1): a 17 mm diameter clamping ring, a $9 \mathrm{~mm}$ diameter sleeve and a $5.3 \mathrm{~mm}$ diameter pin. The outer diameters of the pin and sleeve are 5.2 and $9 \mathrm{~mm}$, respectively. The RFSSW process can be briefly divided into four main stages: touchdown and preheating (Fig. 1a), plunging (Fig. 1b), refilling (Fig. 1c), and retreating (Fig. 1d). After the touchdown stage (Fig. 1a), the

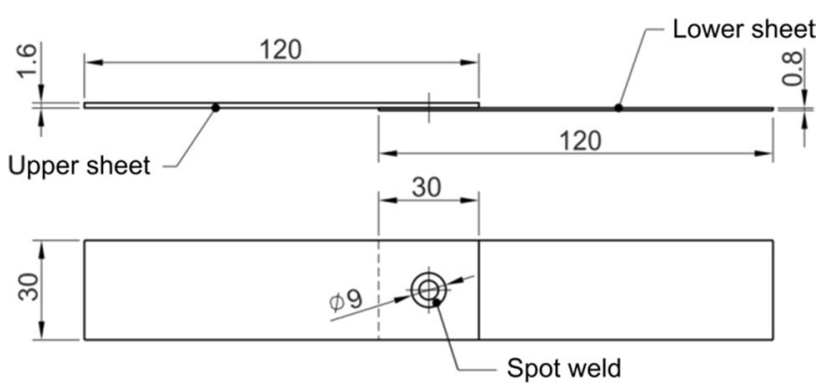

Fig. 2 Shape and dimensions (in $\mathrm{mm}$ ) of the welding specimens

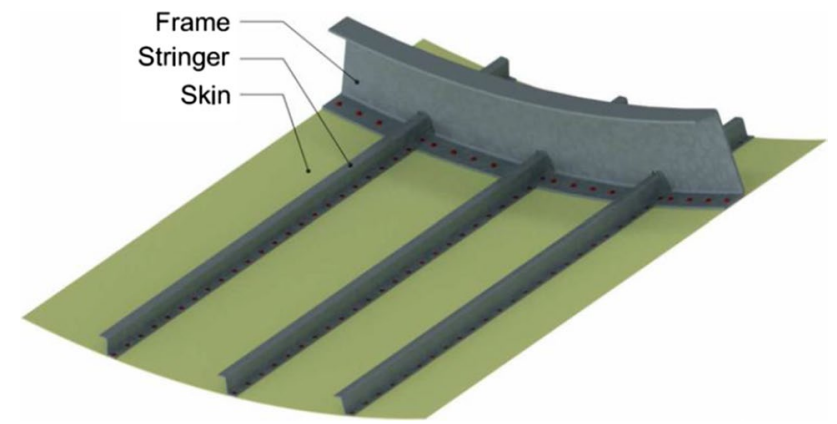

Fig. 3 Structure of the fuselage

tool starts to rotate to preheat the material of the upper sheet. In the plunging stage (Fig. 1b) the rotating sleeve plunges into the metal, while the pin moves upwards. After reaching a certain plunge depth, the sleeve and pin reverse their direction (Fig. 1c) and return back to their original position. Finally, the RFSSW tool is retracted from the workpiece (Fig. 1d).

Specimens were prepared in an overlap joint (Fig. 2), where the thicker sheet is set as the top sheet. This configuration corresponds to the joining of a stringer (1.6 mmthick) to the skin $(0.8 \mathrm{~mm}$-thick) in aircraft structures (Fig. 3). The following welding parameters have been used 
in experiments: clamping force $17 \mathrm{kN}$, tool rotational speed $2600 \mathrm{rpm}$, tool plunge depth $1.5 \mathrm{~mm}$. The welding cycle consists of plunge time $(1 \mathrm{~s})$, stirring time $(1 \mathrm{~s})$ and tool retract time (1 s).

After welding, metallographic analysis was carried out on the specimens from sections made in the centre of the weld. The specimens were polished and etched and the specimens were examined using an Olympus DP700 optical microscope.

\subsection{Temperature measurement}

The temperature distribution in the weld zone is a function of the heat generated by the friction resulting from the contact between the workpiece and the pin and sleeve. The temperature was measured in the vicinity of the weld zone (temp_point_1) and at the external surface of the clamping ring (temp_point_2), according to the scheme in Fig. 4. First a K-type thermocouple was placed in a blind hole $1 \mathrm{~mm}$ in diameter at a distance such that the bottom of the hole was as close as could be to the edge of the weld zone. The second thermocouple was attached to the outer surface of the clamping ring (Fig. 4). The temperature values obtained from the thermocouples were recorded online using a special data logger at a frequency of $1 \mathrm{~Hz}$. This frequency was dictated by limitations of the transducer hardware. We assumed that measurement at characteristic times in the welding process will be sufficient to verify the trend of temperature changes in an FEM simulation. Three specimens have been tested and the average value of the temperature has been determined.

\section{Finite-element modeling}

To better understand the phenomena occurring during welding by RFSSW, there is a need to build a numerical model which would allow a detailed analysis of the phenomena occurring during the weld formation and the relations occurring at the interface of the tool surface and the weld being formed. Firstly, numerical investigations aim to evaluate the model adopted in terms of its compliance with the real process, and after a positive assessment of that model, the analysis of material flow occurring in the welding region. Quantitative validation of the model has been carried out based on the temperature gradient distribution in the weld zone.

The numerical simulation model of the RFSSW process has been conducted using Simufact Forming software (Simufact Engineering Gmbh, Hamburg, Germany). Due to the symmetrical nature of the process $2 \mathrm{D}$ axisymmetric simulation was performed. A fully coupled thermo-mechanical analysis was performed to obtain the temperature distribution in the weld zone and the material flow of the RFSSW process (Fig. 5).

In FE-based simulation of the welding process, a number of simplifications of the numerical model have been adopted in relation to real conditions. Individual elements of the tool, i.e. the pin, sleeve and clamping ring in the FE model, were adopted as cylindrical bodies with smooth surfaces. So the characteristic grooves made on the outer surfaces of the pin and sleeve were omitted. Due to the relatively small plunge depths of the pin and sleeve these grooves do not significantly affect the welding process conditions in the case of
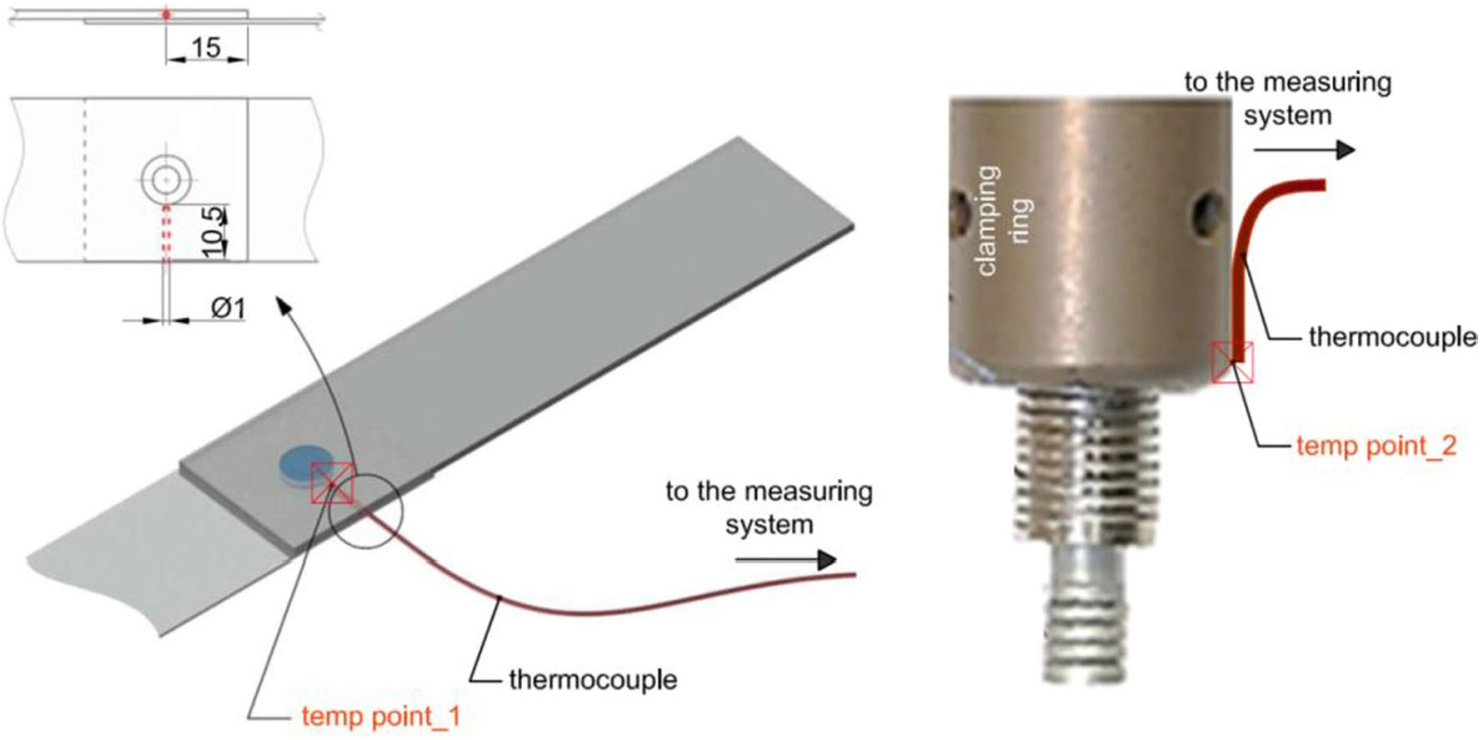

Fig. 4 Locations of thermocouples 


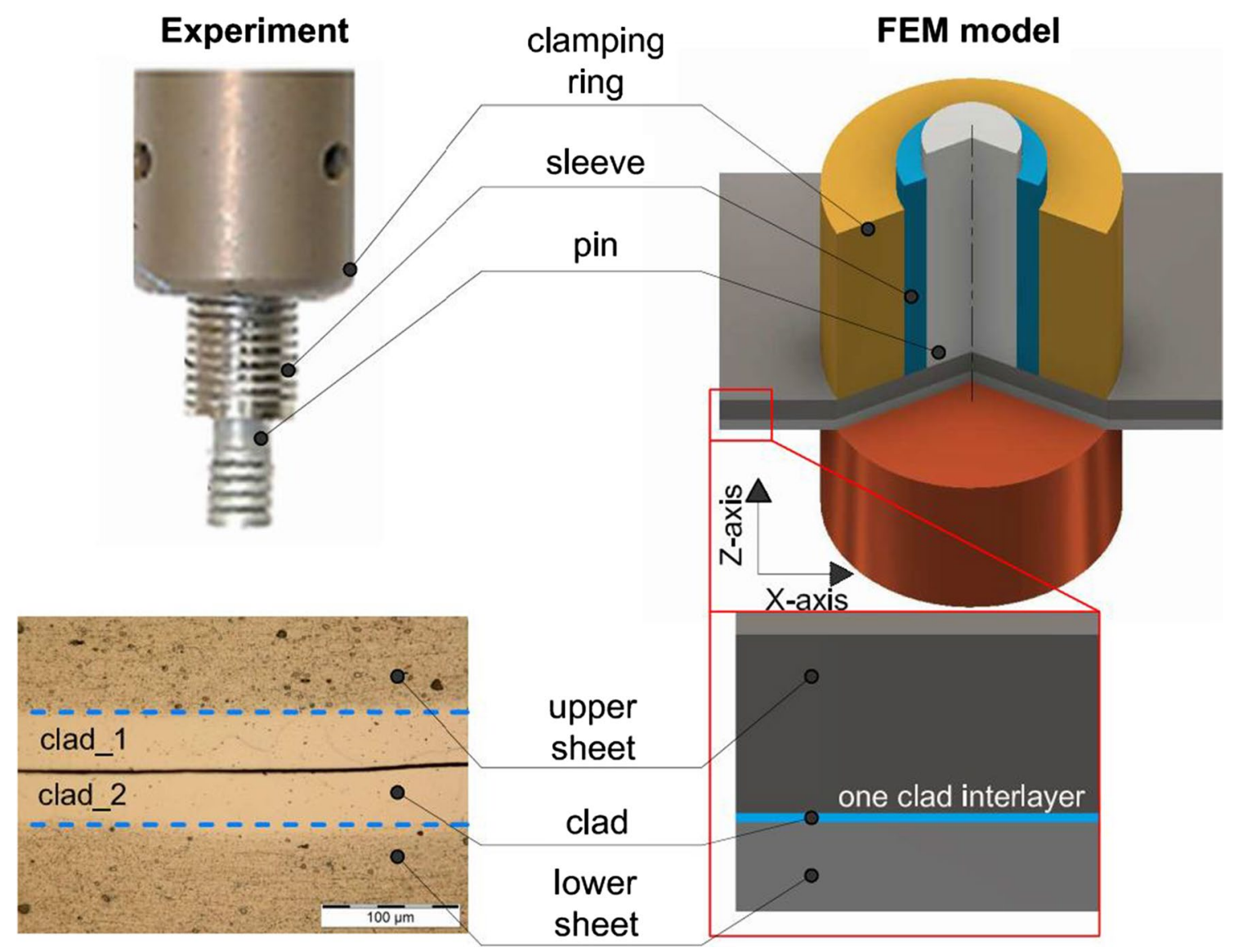

Fig. 5 Assumptions made in the geometry of the RFSSW numerical model

joining thin sheets. The sleeve, pin and clamping ring were all considered as rigid bodies. It is well known that clad layers have a significant effect on heat distribution during the welding process due to the significantly higher thermal conductivity of clad material in relation to the material of the base plate. Therefore, the model consists of an intermediate layer between sheets to reflect the properties of the clad. The thickness of the clad layer in the numerical model was equal to the sum of the clad layers on both the upper and lower sheets. The model simplifications described are shown graphically in Fig. 5. The tool rotational speed and tool displacements corresponded to the experimental conditions (Fig. 6).

The sheets and clad were modelled with 2D elements, destined for the analysis of 2D axisymmetric problems, called Quad(10) in Simufact Forming terminology [22]. Rigid tools were modelled with quad elements called Quad(40) [22]. The initial mesh (Fig. 7) was generated using Advanced Front Quad mesher. In simulating the RFSSW the initial mesh gets distorted due to the large displacement and does not fit the required mesh quality anymore. Excessive mesh distortion of the FE-based model leads to a divergence problem. To avoid the mesh causing too much distortion of the elements an automatic remeshing that automatically regenerates the mesh was used and the simulation is continued using the new mesh. The sheets and clad models were composed of 3474 elements, the rigid bodies consisted of 4549 elements.

The properties of the base material and clad (Table1) have been used from the materials database included in Simufact Forming software [22]. A temperature and strain rate dependent material model built in this software is based on the MatiLDa database which is a registered trademark of Gesellschaft für metallurgische Technologie- und Softwareentwicklung $\mathrm{mbH}$ (Berlin, Germany) according to the following model:

$\sigma_{F}=C_{1} \cdot e^{\left(C_{2} \cdot T\right)} \cdot \varepsilon_{p}^{\left(n_{1} \cdot T+n_{2}\right)} \cdot \varepsilon_{p}{ }^{\left(\frac{l_{1} \cdot T+l_{2}}{\varphi}\right)} \cdot \dot{\varepsilon}_{p}{ }^{\left(m_{1} \cdot T+m_{2}\right)}$

where $T$-temperature, $\varepsilon_{p}$ - plastic strain, $\dot{\varepsilon_{p}}$ - plastic strain rate, $C_{1}, C_{2}, n_{1}, n_{2}, l_{1}, l_{2}, m_{1}, m_{2}$ are parameters which are determined based on the experimental data fitted by the plasticity model [Eq. (1)]. The values of the parameters in the plasticity model are listed in Table 2. The Simufact Forming software does not provide the detailed procedure for the determination of these parameters. 
Fig. 6 Stages of the RFSSW process considered in the numerical model

Fig. 7 Finite-element mesh of the $2 \mathrm{D}$ axisymmetric model
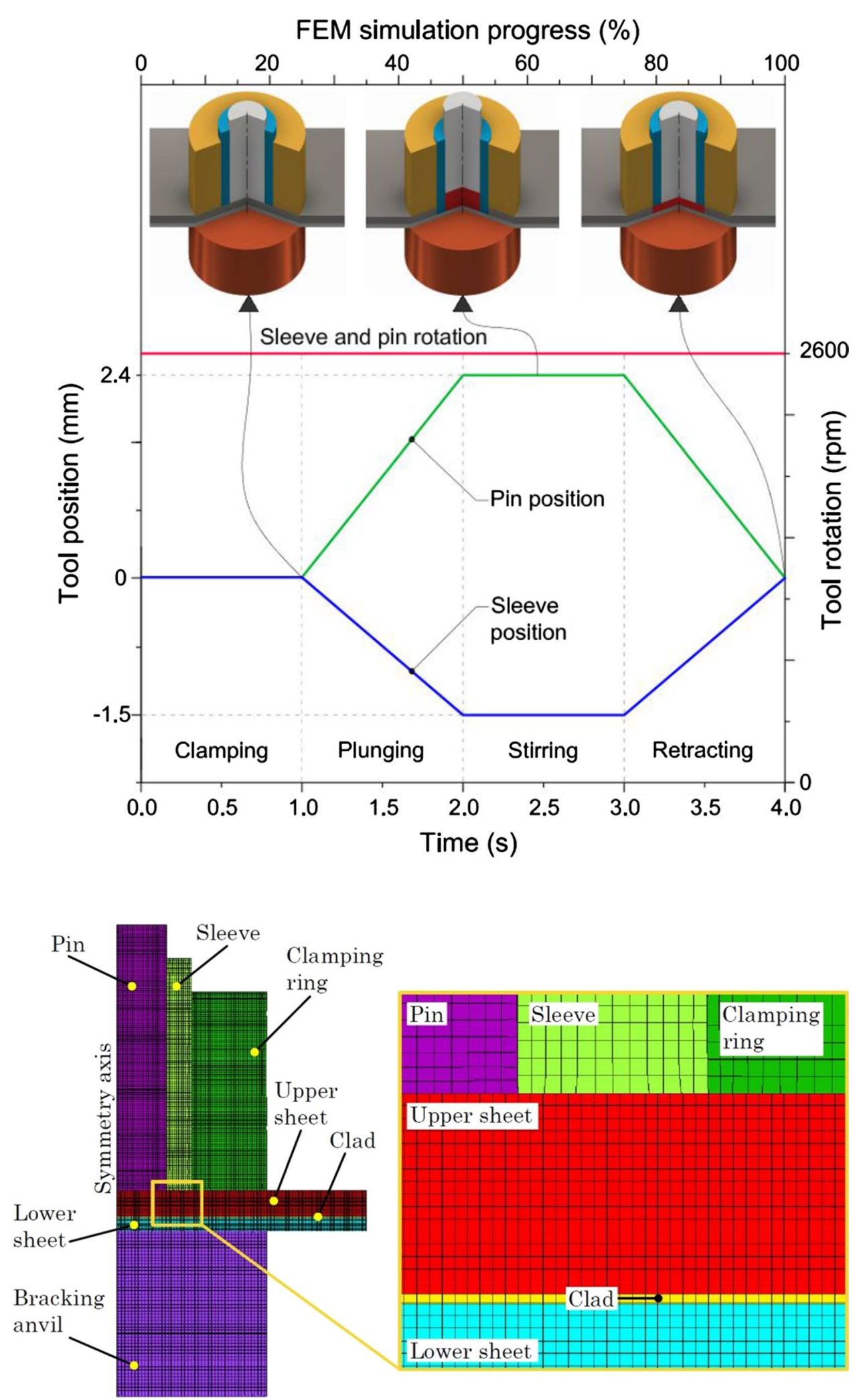
Table 1 Basic mechanical properties of 7075-T6 aluminium alloy sheets

\begin{tabular}{lll}
\hline $\begin{array}{l}\text { Yield stress } R_{p 0.2} \\
(\mathrm{MPa})\end{array}$ & $\begin{array}{l}\text { Ultimate tensile stress } \\
R_{m}(\mathrm{MPa})\end{array}$ & $\begin{array}{l}\text { Elongation at fracture } \\
A, \%\end{array}$ \\
\hline 461.78 & 531.23 & 9.32 \\
\hline
\end{tabular}

The governing equation for the analysis of heat transfer may be written as [23]

$\rho c=\frac{\partial T}{\partial t}=\frac{\partial}{\partial x}\left(k_{x} \frac{\partial T}{\partial x}\right)+\frac{\partial}{\partial y}\left(k_{y} \frac{\partial T}{\partial y}\right)+\frac{\partial}{\partial z}\left(k_{z} \frac{\partial T}{\partial z}\right)+\dot{q}_{p}$

where $\rho$ is the material density, $c$ is the specific heat, $t$ is time, $T$ is temperature, $\dot{q}_{p}$ is the heat generation coming from plastic energy dissipation, and $x, y, z$ are the spatial coordinates.

The rate of heat generation due to plastic energy dissipation may be determined based on the equation:

$\dot{q}_{p}=\tau \eta \dot{\varepsilon}_{p}$

where $\tau$ is the shear stress, $\eta$ is the factor of conversion of mechanical to thermal energy.

The heat generated by friction between the tool surfaces and the workpiece is computed from

$\dot{q}_{f}=\mu p \dot{\gamma}$

where $\dot{q}_{f}$ is the frictional heat generation, $\mu$ is the coefficient of friction, $p$ is the contact pressure, and $\dot{\gamma}$ is the slip rate.

The moment required to rotate a circular tool relative to the workpiece surface under the plunging stage is derived by [23]

$M=\int_{0}^{R} 2 \pi \mu \operatorname{Pr}^{2} d r$

where $R$ is the surface radius and $P$ is the traction.

The heat generated in friction stir spot welding is exchanged with the surroundings by radiant and convective loss [24]. For the convective heat loss, $q_{c}$ :

$q_{c}=h_{f}\left(T_{s}-T_{\infty}\right)$

where $h_{f}$ is the convection coefficient $\left(h_{f}=50 \mathrm{~W} / \mathrm{m}^{2}{ }^{\circ} \mathrm{C}\right), T_{s}$ is the temperature at the plate surfaces and $T_{\infty}$ is the absolute temperature of the surroundings $\left(T_{\infty}=20^{\circ} \mathrm{C}\right)$.

For the radiant heat loss, $q_{r}$ $q_{r}=\kappa \varepsilon_{r}\left(T_{r}^{4}-T_{\infty}^{4}\right)$

where $\kappa$ is the Stefan-Boltzmann constant $\left(\kappa=5.67 \cdot 10^{-8} \mathrm{~W} /\right.$ $\left.\mathrm{m}^{2}{ }^{\circ} \mathrm{C}\right), T_{r}$ is th absolute temperature of the radiating surface and $\varepsilon_{r}$ is the emissivity of the radiating surface $\left(\varepsilon_{r}=0.5\right)$ [24].

The Young's modulus, thermal expansion coefficient, thermal conductivity coefficient and heat capacity are temperature dependent parameters, which are used in this simulation to acquire accurate results. The relationship of these parameters with temperature has been built in the material database of the Simufact Forming software [22]. The remaining parameters used in the simulation are listed in Table 3.

During friction stir welding of 7000 series aluminium alloy sheets, local melting of the material may occur [25, 26]. This phenomenon may lead to a reduction in the friction heat generation rate $[27,28]$. The second-phase particles in 7075-T6 base metal began to melt spontaneously when the temperature was higher than $475{ }^{\circ} \mathrm{C}$. The $\eta, \mathrm{S}$, and $\mathrm{T}$ particles melt spontaneously when the stir zone temperature reaches 475,480 and $490{ }^{\circ} \mathrm{C}$, respectively $[25,29]$. On the other hand when the temperature was up to $532{ }^{\circ} \mathrm{C}$, the homogenised 7075 aluminium alloy (T6 temper) began to melt [30]. Thus, following the study of Zhen et al. [30], a constant shear friction model was used for the whole simulation process. The friction factor value changed according to temperature (Fig. 8), in line with the study by Song et al. [31] and Zhen et al. [30]."

\section{Results and discussion}

\subsection{Characterisation of the weld zone}

To assess the degree of compliance of the numerical model with the real welding process, the cross section of the weld structure was first analysed by comparing it with the cross section of the real joint. The views of the cross section of numerically predicted material flow in the weld and the

Table 3 Density and Poisson's ratios of the materials analysed

\begin{tabular}{lll}
\hline Material & Poisson's ratio $\nu$ & Density $\rho, \mathrm{kg} \cdot \mathrm{m}^{3}$ \\
\hline 7075-T6 (BM) & 0.25 & 2795 \\
Pure aluminium (clad) & 0.25 & 2689 \\
\hline
\end{tabular}

Table 2 Parameters in the plasticity model of base metal and clad

\begin{tabular}{llllrlllr}
\hline Material & $C_{1}$ & \multicolumn{1}{l}{$C_{2}$} & $n_{1}$ & \multicolumn{1}{l}{$n_{2}$} & \multicolumn{1}{l}{$l_{1}$} & $l_{2}$ & $m_{1}$ & \multicolumn{1}{c}{$m_{2}$} \\
\hline Base metal & 506.5 & -0.000444 & $-4.81 \times 10^{-5}$ & -0.1061 & $5.756 \times 10^{-5}$ & -0.028 & 0.000265 & -0.0109 \\
Clad & 203.2 & -0.00404 & -0.000274 & 0.1973 & $2.573 \times 10^{-5}$ & -0.012 & 0.000332 & 0.0081 \\
\hline
\end{tabular}




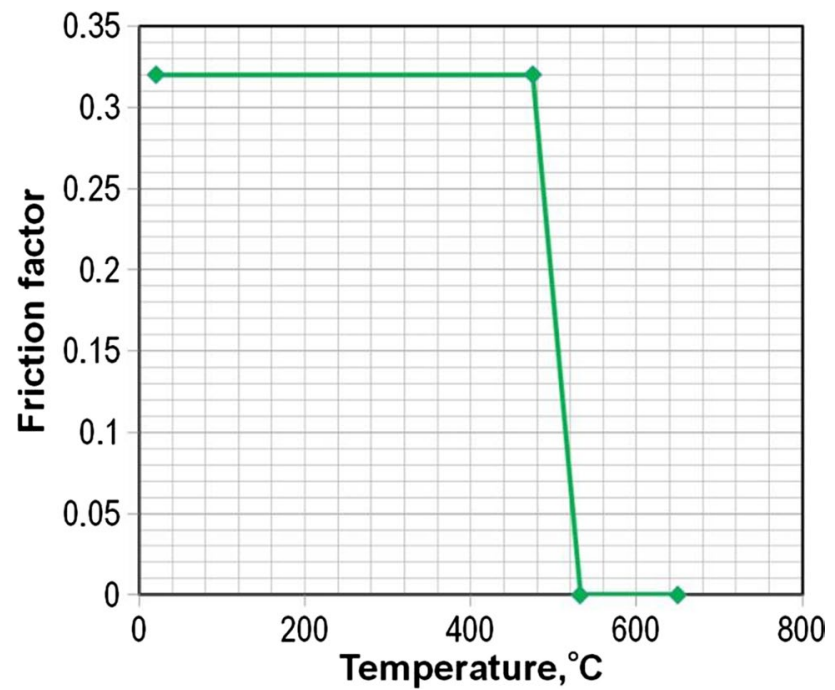

Fig. 8 Variation of friction factor $v s$. temperature

cross section of the fabricated weld are shown in Fig. 9a, $\mathrm{b}$, respectively. The cross section of the RFSSW joints can be divided into four regions in terms of the microstructural characteristics of the joint [19]: the stir zone (SZ), the thermo-mechanically affected zone (TMAZ), the heat affected zone (HAZ) and the base material (BM). The stir zone is characterised by dynamically recrystallised equaxial grains.

From Fig. 9, one can see that the distribution of the clad layer is similar in both cases. In the central part of the weld the clad has increased thickness and this slightly increases towards the face of weld. At the corner of the weld, the plating layer splits and determines the direction of material flow in the final stage of welding. The nature of the plating behaviour in the corner of the weld model coincides with the real case. Due to the simplifications in the model adopted, the criterion of destruction of the plating layer was not applied. Therefore, it does not break in the model, which should in fact occur.

The incomplete refilling defect is located on the surface of the upper sheet (Fig. 10) and is attributed to insufficient flow of the stirred material at the refilling stage [18]. A convergence may be noticed between the results of FEM and those of the experiment.

\subsection{Contact pressure}

In the next stage of the verification of the FEM model, the value of the clamping ring pressure was determined in the numerical model. The role of the clamping ring in the first stage of RFSSW is to hold the workpieces firmly in contact during the welding process. Moreover, clamping pressure prevents the sheets from separating as the plasticised material is displaced by the pin and sleeve. Figure 11 shows the contact pressure distribution on the contact surfaces of the individual elements. Considering the contact area of the clamping ring with the upper sheet, the clamping induces a contact pressure with a value of approximately $99 \mathrm{MPa}$ which accords very closely with the numerical results (Fig. 11). Such a relatively high pressure causes elastic deflection of the non-supported ends of the sheets being joined.
Fig. 9 View of (a) material flow as predicted by the FE model and $\mathbf{b}$ cross section of the RFSSW joint

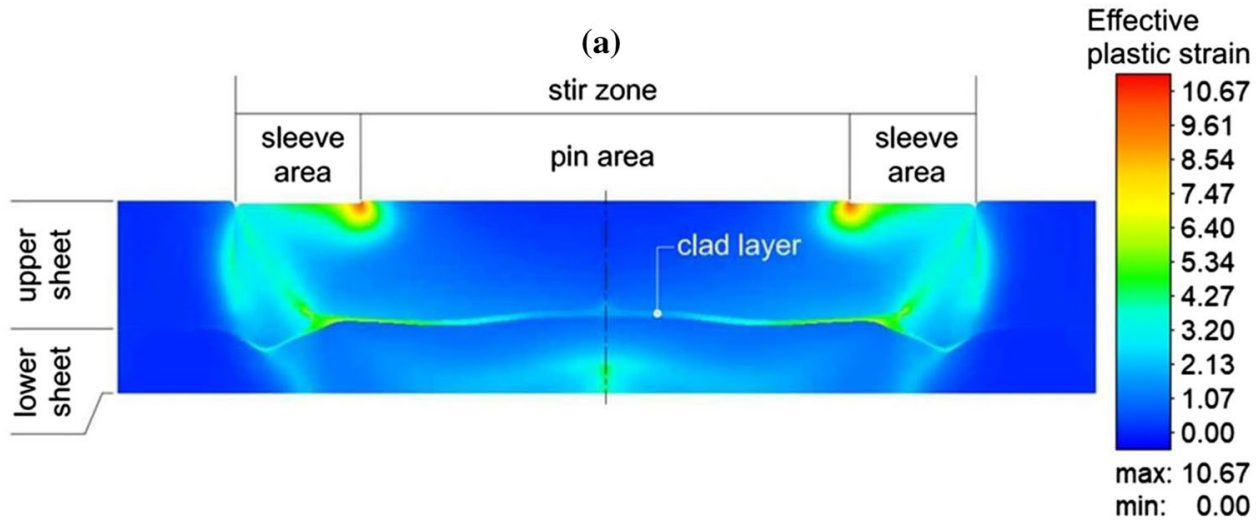

(b)

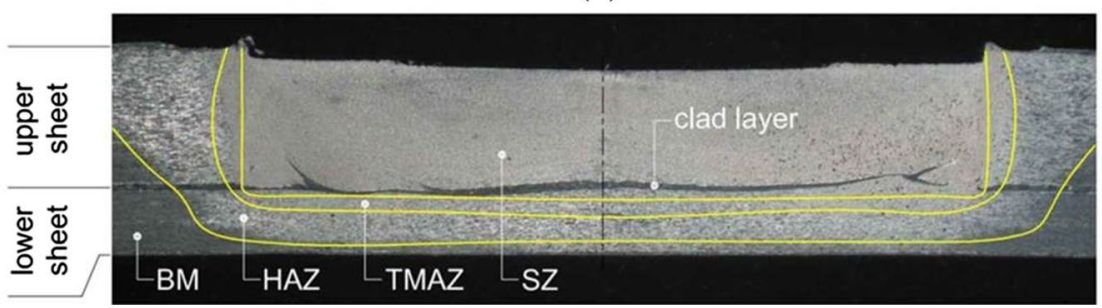



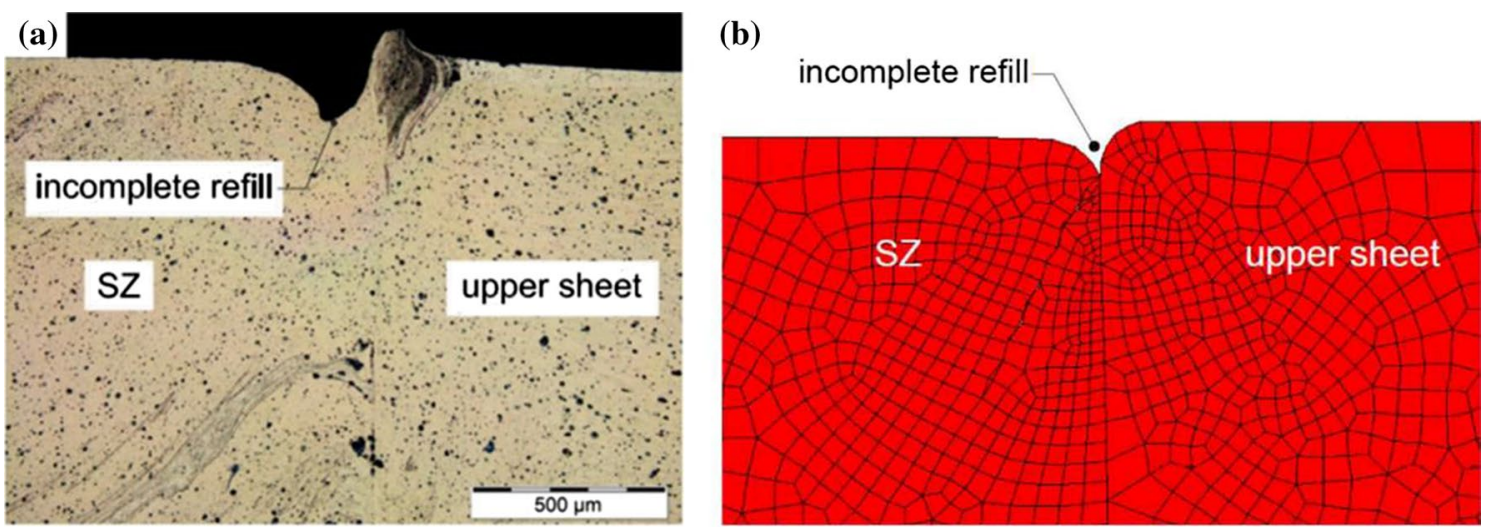

Fig. 10 Defect in the form of incomplete refill: a cross section of an experimentally formed joint and $\mathbf{b}$ result of numerical computations
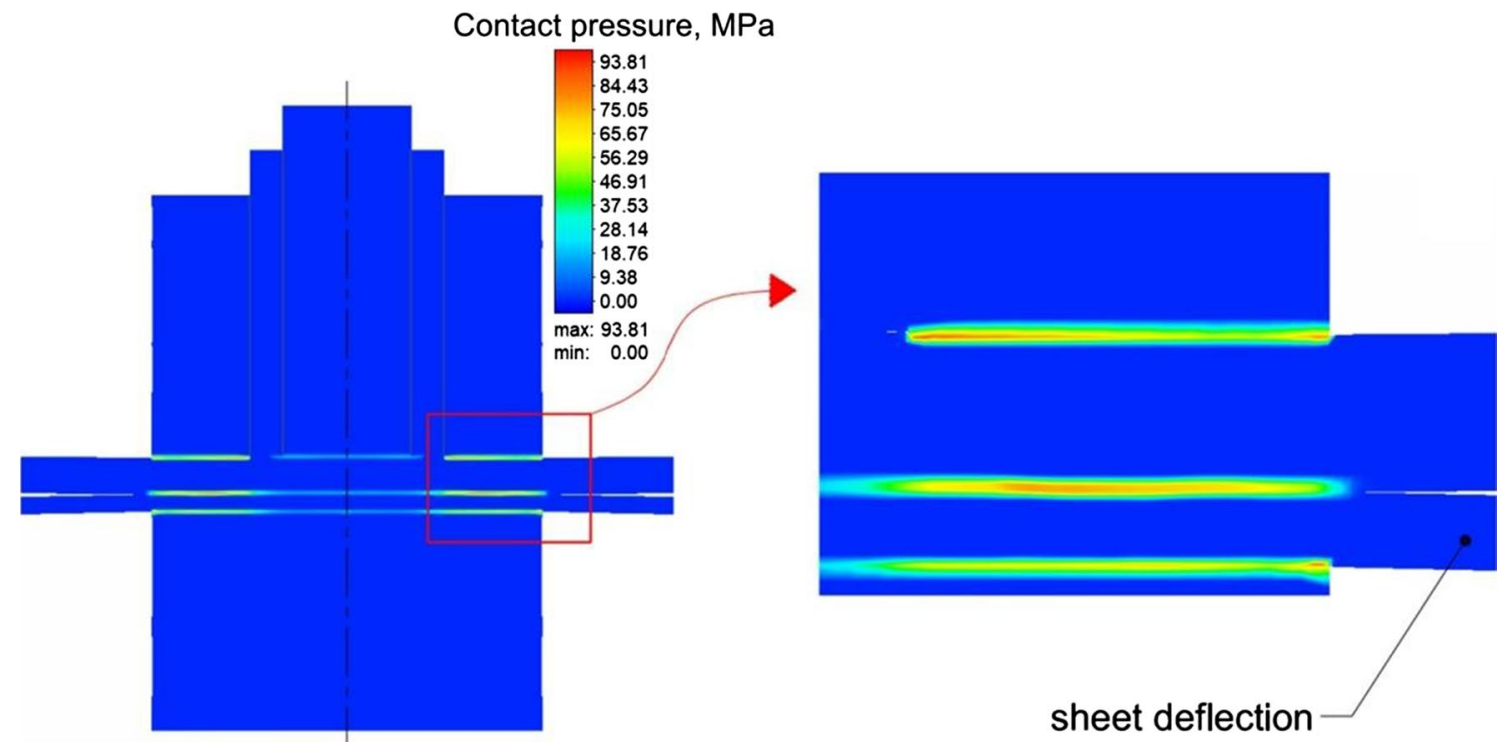

Fig. 11 Distribution of contact pressure induced by clamping ring pressure in the first stage of the RFSSW process

\subsection{Temperature distribution}

The heat generated by the friction effect between the tool and workpiece affects the physical properties of the workpiece and tool. Heat is also a result of plastic deformation in the region of the welding [32]. Comparison of the experimentally and numerically obtained results of the time-dependence of temperature during the whole welding cycle is shown in Fig. 12. The initial temperature for the numerical model was $20{ }^{\circ} \mathrm{C}$. In the first $2 \mathrm{~s}$ of the preheating and plunge stage, the temperature increases very quickly in the area of the weld zone (temp_point_1). During the plunging stage the temperature increases by $250{ }^{\circ} \mathrm{C} / \mathrm{s}$ (Fig. 12a). The maximum temperature at the surface of the upper sheet, measured at temp_point_2, reaches about $180{ }^{\circ} \mathrm{C}$ (Fig. 12b). At the end of the retreat stage, experimental measurements reveal an increase in the temperature at both points analysed. However, the FEM results show a decrease in the temperature which is clearly visible at the point located at the periphery of the clamping ring. This can be attributed to the high thermal inertia of the measuring system.

Taking into account the thermal inertia of the measuring system, it was found that satisfactory accuracy of the temperature measurement results was obtained in the FEM simulation. Therefore, the stage of the process at which the highest temperature is generated, its value and its area of occurrence were indicated. The highest temperature was recorded at $90.3 \%$ of the RFSSW cycle. Its value was $512.74{ }^{\circ} \mathrm{C}$, and it occurs at the point, where the pin front meets the inner edge of the sleeve (Fig. 13). 

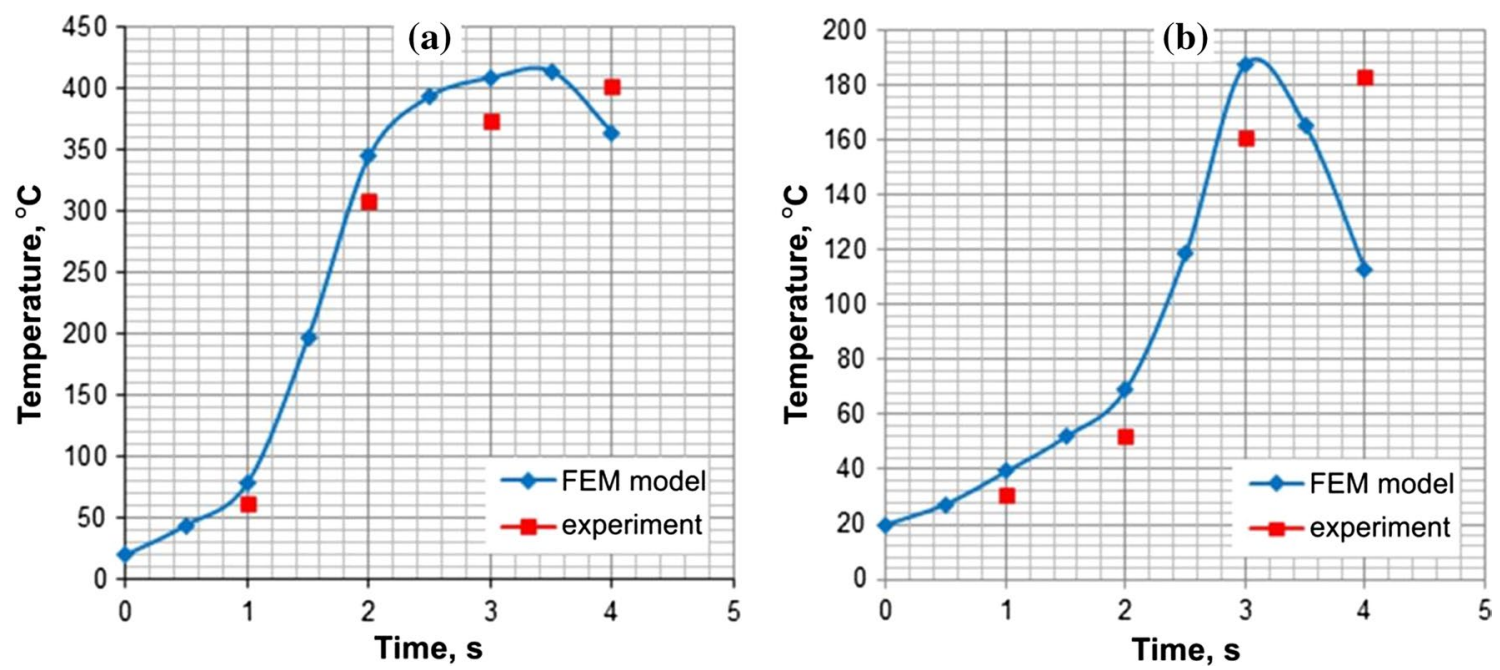

Fig. 12 Temperature variation during the welding process at selected measuring points: a temp_point_1 and b temp_point_2

\subsection{Mechanics of joint formation}

Figures 14, 15 and 16 present the distributions of selected parameters for selected stages of the RFSSW process, i.e. plunging at $29.3 \%$ (Fig. 14) and $50.3 \%$ (Fig. 15) of the total RFSSW cycle and at the refilling stage (Fig. 16). The left edge of the pictures corresponds to the symmetry axis of the joint. The RFSSW process consists of following stages:

- The clamping ring is fixed on the top surface of the upper sheet, and the tool stays there for a certain amount of time to produce initial frictional pre-heating,

- The sleeve plunges the sheet to the desired depth, at the same time the pin moves in the opposite direction,

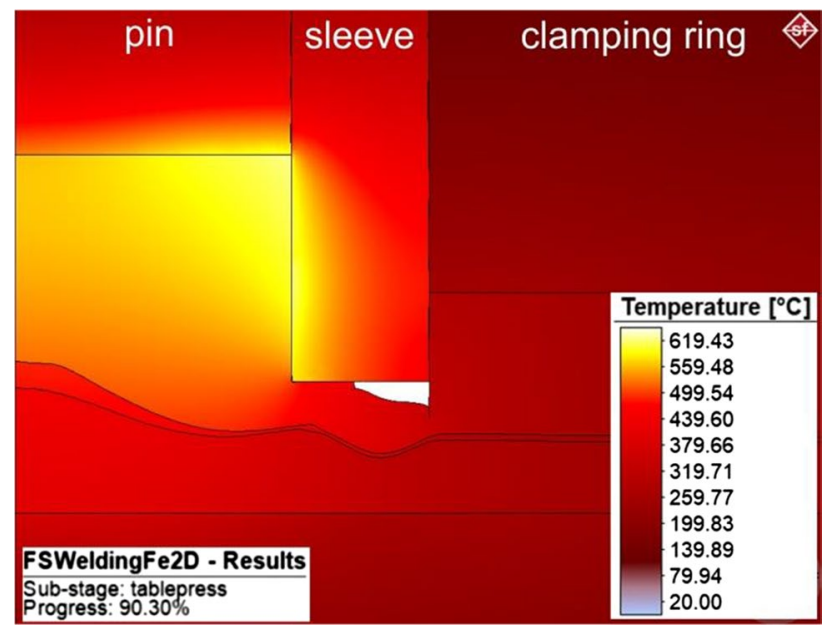

Fig. 13 Distribution of temperature at the interface of the tool and the workpiece at the welding time corresponding to the $90.3 \%$ of the RFSSW cycle
- After reaching the desired plunge depth, the directions of movement of both the sleeve and pin begin to reverse,

- The weld cycle is completed by removing the tool from the surfaces of the sheets.

At the plunging stage the accumulated plastic strain achieves its highest values around the working edges of the pin (Fig. 14a, b). Accumulated plastic strain is defined as a sum of plastic strain increments irrespective of direction and sign [33]. The level of accumulated plastic deformation in the volume of the upper sheet significantly increases under the operating surface of the sleeve (Figs. 15a, 16a). This creates conditions for the formation of a fine-grained structure throughout the volume of the lower edge of the joint. A severe accumulated plastic strain allows the formation of new grain boundaries which are fundamental in the dynamic recrystallisation process.

At the plunging stage, clear flexure of both the lower and upper sheets of the material is observed. Furthermore, material of the lower sheet situated under the action surface of the sleeve is squeezed out into the middle part of the weld by the material of the upper sheet (Fig. 16b, c). The clad layer separates the regions of the upper sheet and lower sheet which are characterised by considerably different amounts of effective stress (Figs. 14b, 15b and 16b).

Metallurgical zones in the cross section of the weld are shown in Fig. 17. Different orientation and grain size in the central part of both the upper and lower sheets is observed at a certain distance from the weld edge. It can be concluded that there was a significant effect of heat on the microstructure of the material of the joined sheets. Clear widening of the HAZ may be revealed in the direction of the base material. The location of this zone in the central part of 

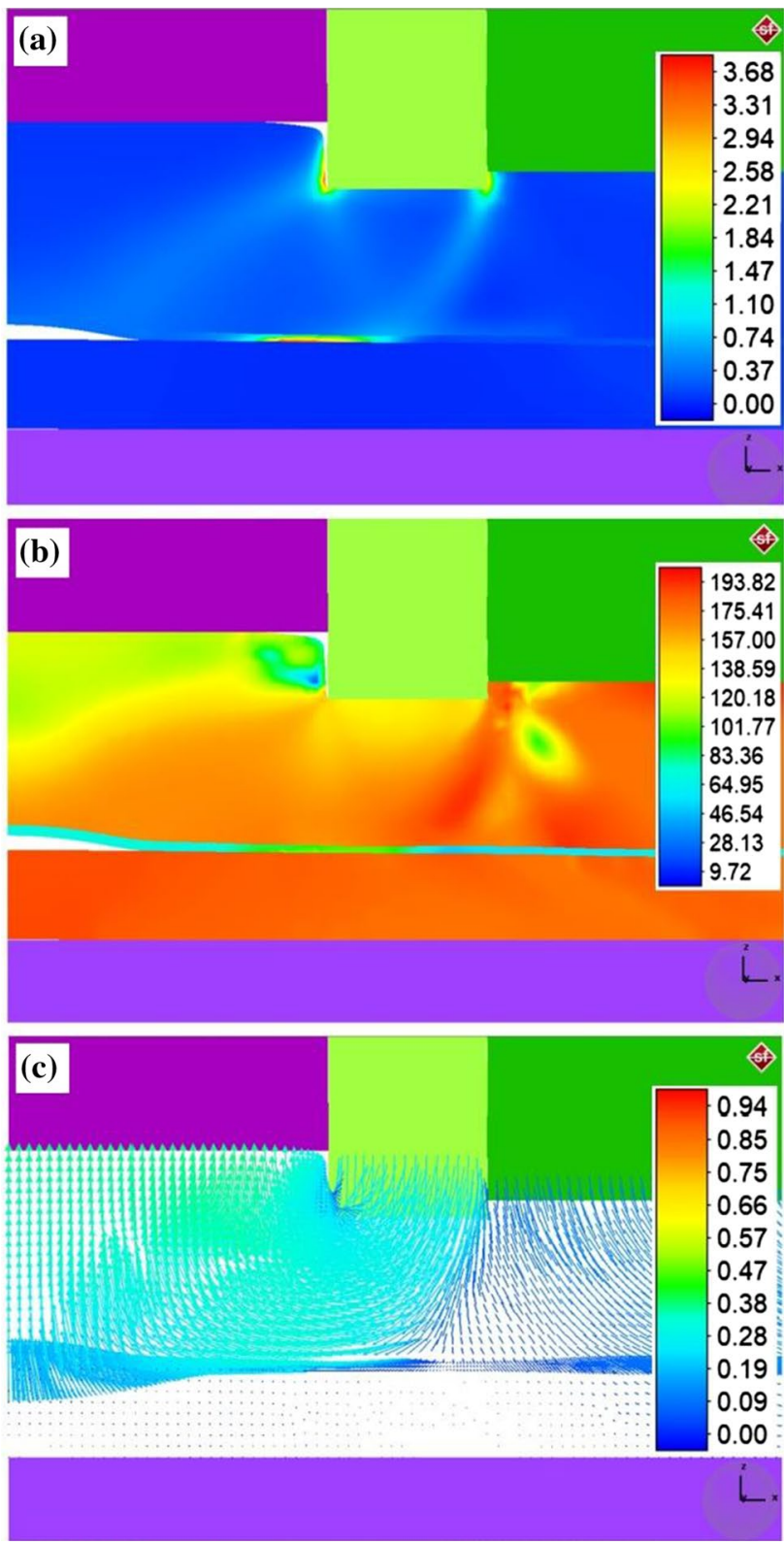

Fig. 14 View of the deformation in the weld zone at $29.3 \%$ of the RFSSW cycle: a accumulated plastic strain, $\mathbf{b}$ effective stress (MPa), c displacement vector (mm)

the overlapped sheets indicates that there was intense heat dissipation due to a clear difference in thermal conductivity of the clad and BM. The thermal conductivities of the base material and the clad are $134 \mathrm{~W} / \mathrm{mK}$ and $229 \mathrm{~W} / \mathrm{mK}$, respectively. This difference arises, because the clad transfers the heat out of the joint more rapidly than does the BM.

Qualitative assessment of the results of numerical modelling is possible based on an analysis of the direction of material flow at the final stage of welding in specific regions of the weld structure. The arrangement of the clad layers in the weld is a specific determinant and illustrates the direction of
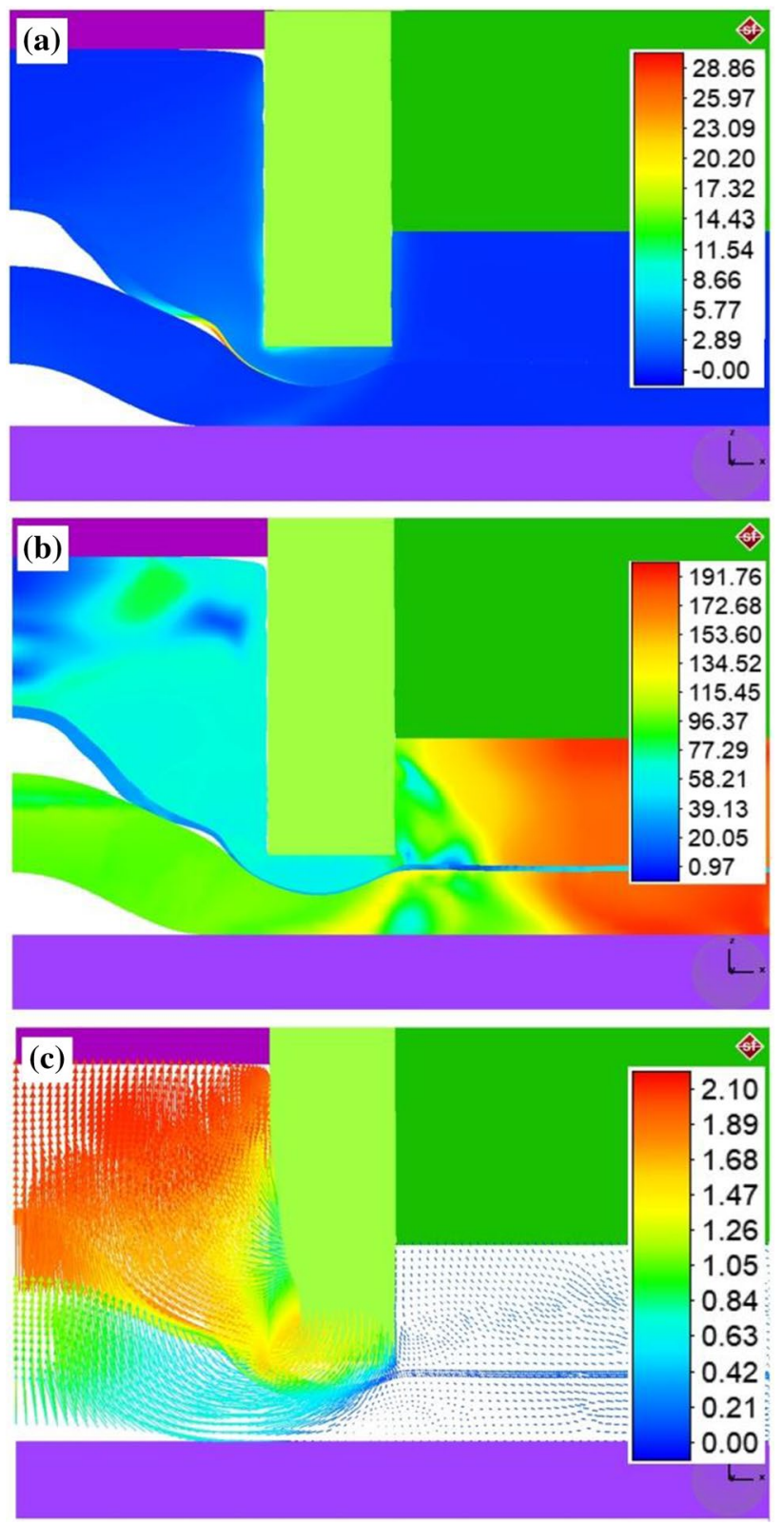

Fig. 15 View of the deformation in the weld zone at $51.3 \%$ of the RFSSW cycle: a accumulated plastic strain, $\mathbf{b}$ effective stress (MPa), c displacement vector $(\mathrm{mm})$

material flow during the refilling stage of RFSSW. The grain orientation and degree of grain refinement in the joint structure are also helpful in assessing the hypothetical flow direction of material. A comparison of the weld microstructure with clear bands of clad and the direction of material flow indicated at the refilling stage for the experimentally obtained and numerically predicted joint structures is shown in Fig. 18a, b, respectively. The numerical model does not take into account the degradation of the clad layer as a criterion. However, there is a good match between the vectors of material flow in the experiment and the hypothetical material flow in the weld (Fig. 18a). The 

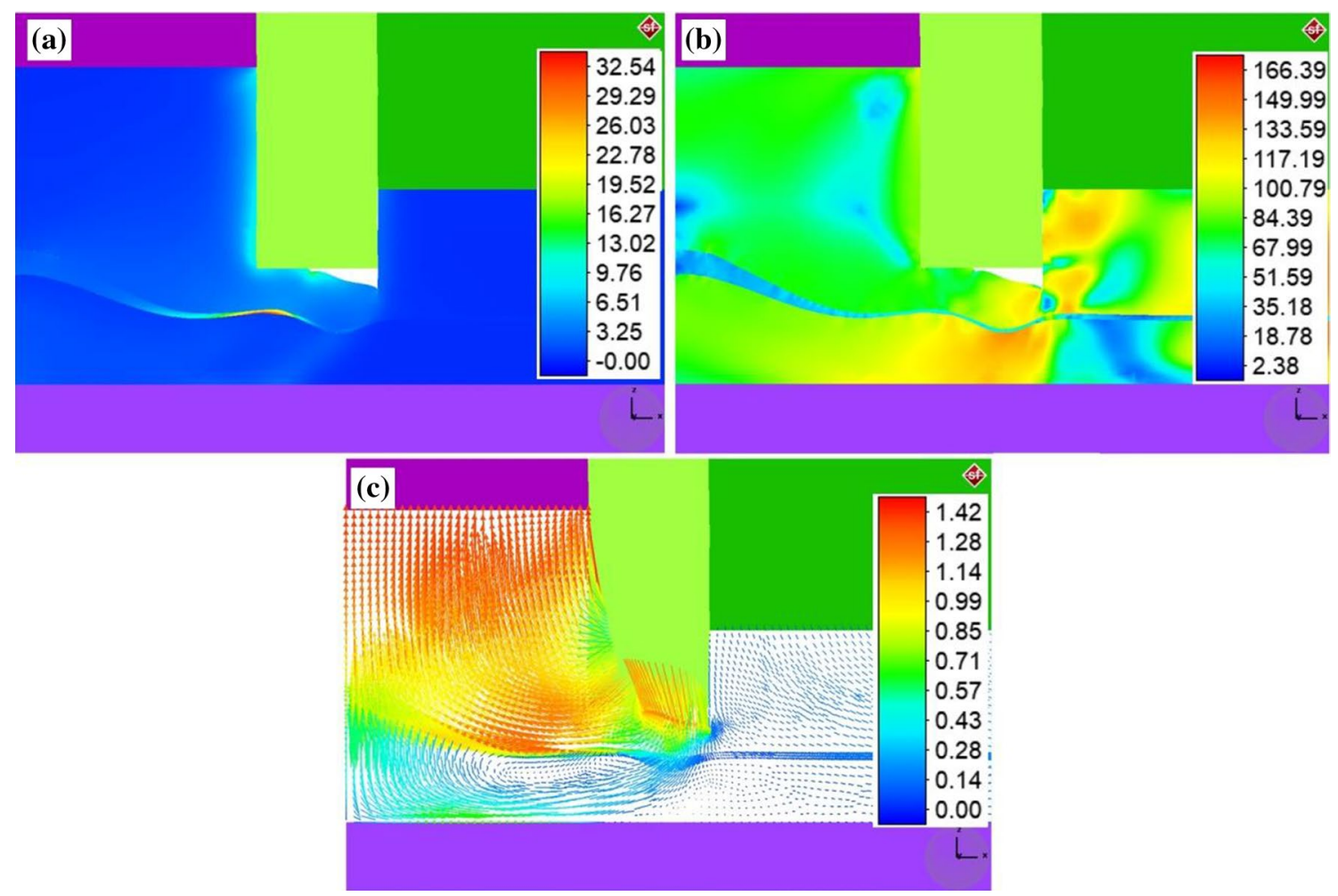

Fig. 16 View of the deformation in the weld zone at 85.4\% of the RFSSW cycle: a accumulated plastic strain, $\mathbf{b}$ effective stress (MPa), $\mathbf{c}$ displacement vector $(\mathrm{mm})$

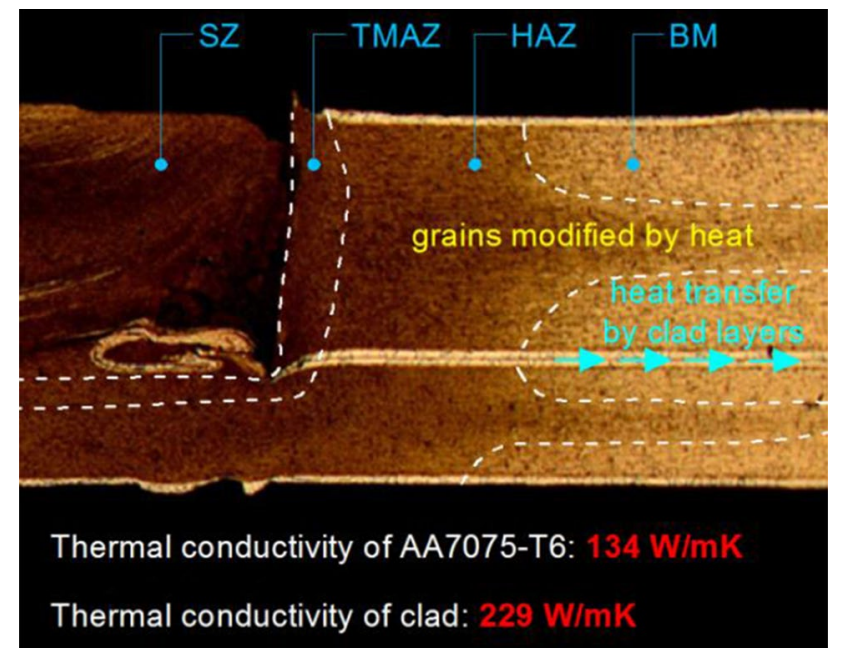

Fig. 17 Cross-sectional view of the edge of an RFSSW joint

analysis of material flow in the RFSSW weld has been studied by Ji et al. [34] based on the finite-volume model. They concluded that low flow velocity in the joint centre leads to clad concentration, which easily results in shear fracture. Knowledge of the direction of material flow allows one to predict the structural defects that can arise with inappropriately selected parameters for the RFSSW.

A view of the final configuration of the joint components is shown in Fig. 19. Typical defects of the RFSSW joint are visible, i.e. incomplete refill and a structural notch between base material of the upper sheet and the stirred area of the weld below the sleeve surface. The reason for the formation of incomplete refilling is insufficient plasticity of the material that came from the upper region of the sleeve cavity and which is used to refill the annular cavity created when the sleeve retracts. Insufficient plasticity of material may result from lower heat generation in this weld zone in comparison with the area at the bottom of the sleeve surface. The structural notch on the circumference of the weld is an effect of sleeve penetration towards the upper sheet. The size of the structural notch depends largely on the tool plunge depth and this size has a considerable influence on the load capacity of the joint.

\section{Conclusions}

This paper investigated the material flow and temperature distribution in RFSSW of Alclad 7075-T6 aluminium alloy sheets by finite-element-based numerical simulation. The following conclusions are drawn from the research: 
Fig. 18 Direction of material flow at the refilling stage based on (a) the distribution of clad layer in a cross-sectional view of the RFSSW joint and $\mathbf{b}$ the displacement vector of the nodes in the numerical model

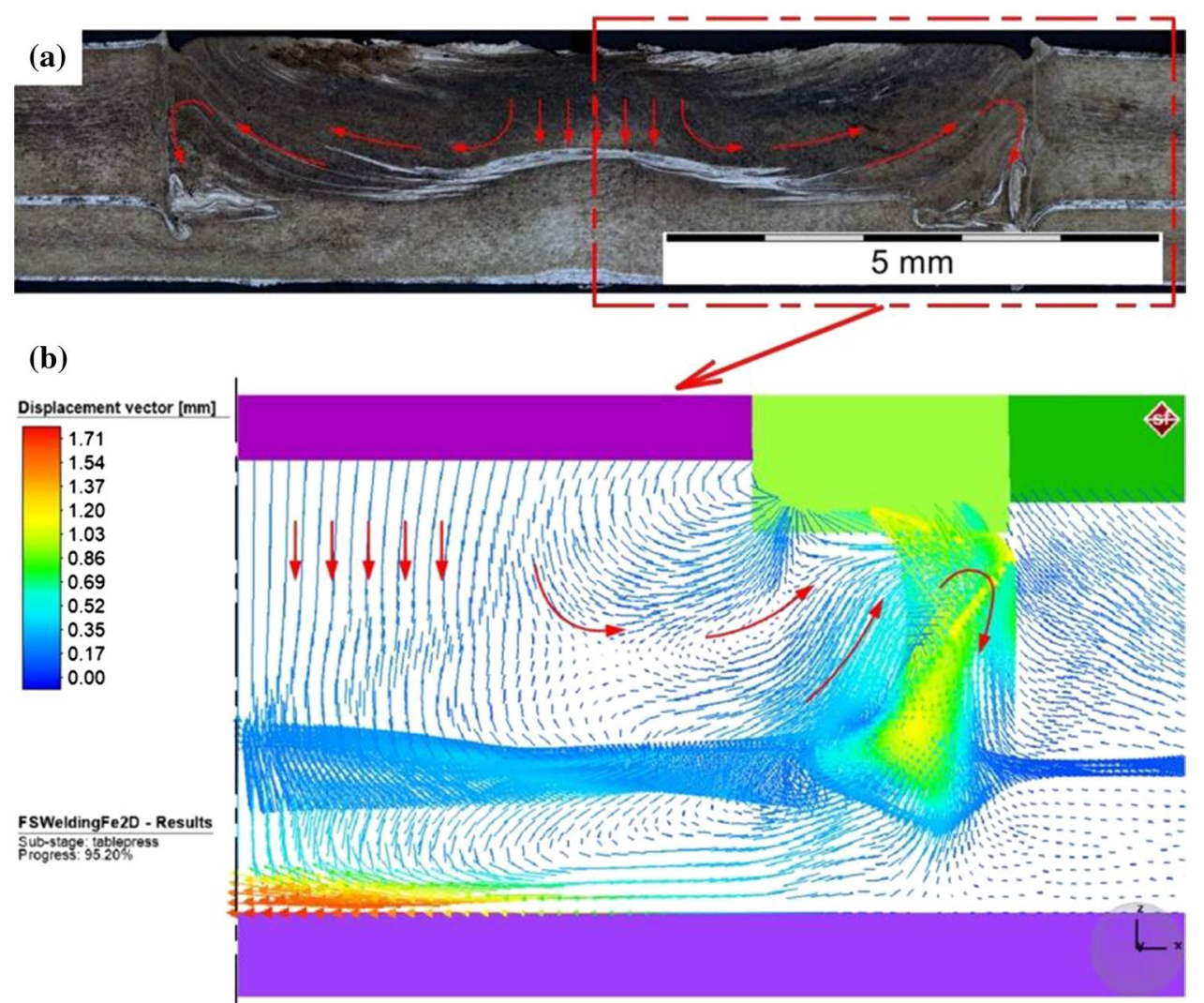

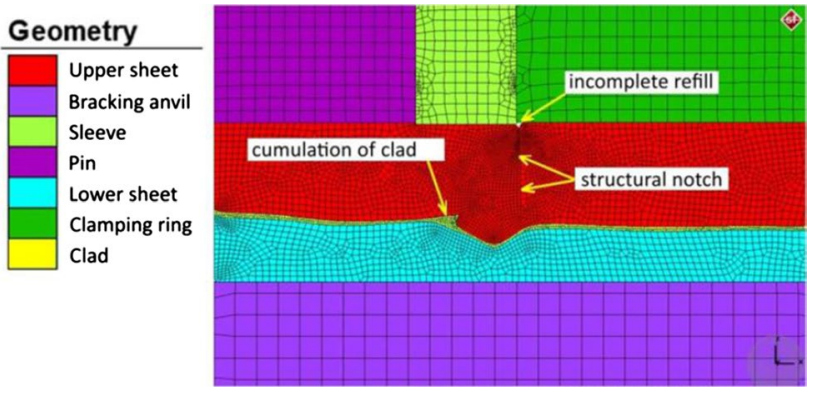

Fig. 19 Final configuration of the joined sheets

- The material flow in an FE-based model is largely consistent with an experimentally fabricated joint; the character of clad behaviour in the corner of the weld model coincides with that seen in the real case,

- The temperature in the weld zone increases quickly during the plunging stage, in the area close to the edge of the weld the temperature increases at $250{ }^{\circ} \mathrm{C} / \mathrm{s}$; although, during the plunging and refilling stages the numerical results are consistent with the results obtained experimentally,

- The highest temperature occurred at the point, where the pin front meets the inner edge of the sleeve reaching approximately $512{ }^{\circ} \mathrm{C}$ at $90 \%$ of the RFSSW cycle time,
- Clad acts as a thermal insulator through a barrier effect and so inhibits homogeneous heat transfer in the weld difficult.

Acknowledgements The authors of this paper would like to kindly thank Dr. Koen Faes from the Belgian Welding Institute for the help in experiments of the RFSSW.

Author contribution Conceptualization: AK; Experiments: AK; Numerical modelling: AK with help of TT; Writing —original draft preparation: TT; Writing - review and editing: AK, TT. All authors read and approved the final manuscript.

Funding This research received no external funding.

Data availability The raw/processed data required to reproduce these findings are not shared.

Code availability Not applicable (The authors used commercial software).

\section{Compliance with ethical standards}

Conflict of interest The authors declare no conflict of interest.

Ethical approval The authors declare the compliance with the ethical standards. 
Open Access This article is licensed under a Creative Commons Attribution 4.0 International License, which permits use, sharing, adaptation, distribution and reproduction in any medium or format, as long as you give appropriate credit to the original author(s) and the source, provide a link to the Creative Commons licence, and indicate if changes were made. The images or other third party material in this article are included in the article's Creative Commons licence, unless indicated otherwise in a credit line to the material. If material is not included in the article's Creative Commons licence and your intended use is not permitted by statutory regulation or exceeds the permitted use, you will need to obtain permission directly from the copyright holder. To view a copy of this licence, visit http://creativecommons.org/licenses/by/4.0/.

\section{References}

1. Schilling C, Dos Santos J. Method and device for joining at least two adjoining work pieces by friction welding, U.S. Patent 0179 682, 2002.

2. Yang HG, Yang HJ, Hu X. Simulation on the plunge stage in refill friction stir spot welding of aluminum alloys. Proceedings of the 4th International Conference on Mechatronics Materials Chemistry and Computer Engineering, Xi' an, China, 12-13 December 2015, pp. 521-524.

3. Muci-Küchler KH, Kalagara S, Arbegast WJ. Simulation of a refill friction stir spot welding process using a fully coupled thermomechanical FEM model. J Manuf Sci Eng. 2010;132(1):014503.

4. Cao JY, Wang M, Kong L, Yin YH, Guo LJ. Numerical modeling and experimental investigation of material flow in friction pot welding of Al 6061-T6. Int J Adv Manuf Technol. 2017;89:2129-39.

5. D'Urso G, Giardini C. Thermo-mechanical characterization of friction stir spot welded AA7050 sheets by means of experimental and FEM analyses. Materials. 2016;9(8):689.

6. D'Urso G, Longo M, Giardini C. Friction stir spot welding (FSSW) of aluminum sheets: experimental and simulative analysis. Key Eng Mater. 2013;549:477-83.

7. Malik V, Sanjeev NK, Hebbar HS, Kailas SV. Finite element simulation of exit hole filling for friction stir spot welding - a modified technique to apply practically. Proced Eng. 2014;97:1265-73.

8. Yang X, Feng W, Li W, Xu Y, Chu Q, Ma T, Wang W. Numerical modelling and experimental investigation of thermal and material flow in probeless friction stir spot welding process of Al 2198-T8. J Sci Technol Weld Join. 2018;23(8):704-14.

9. Cox C, Lammlein D, Strauss A, Cook G. Modeling the control of an elevated tool temperature and the effects on axial force during friction stir welding. Mater Manuf Process. 2010;25:1278-82.

10. Atharifar H, Lin D, Kovacevic R. Numerical and experimental investigations on the loads carried by the tool during friction stir welding. J Mater Eng Perform. 2009;18(4):339-50.

11. Chen G, Shi QY, Zhang S. Recent development and applications of CFD simulation for friction stir welding. In: Nacstac L, Pericleous K, Sabau AS, Zhang L, Thomas BG, editors. CFD Modeling and Simulation in Materials Processing. Cham: Springer Nature; 2018. p. 113-118.

12. Venukumar S, Yalagi S, Muthukumaran S. Comparison of microstructure and mechanical properties of conventional and refilled friction stir spot welds in AA 6061-T6 using filler plate. Trans Nonferrous Met Soc China. 2013;23:2833-42.

13. Rosendo T, Parra B, Tier MAD, da Silva AAM, dos Santos JF, Strohaecker TR, Alcântara NG. Mechanical and microstructural investigation of friction spot welded AA6181-T4 aluminum alloy. Mater Des. 2011;32:1094-100.

14. Shen Z, Ding Y, Chen J, Gerlich AP. Comparison of fatigue behavior in $\mathrm{Mg} / \mathrm{Mg}$ similar and $\mathrm{Mg} /$ steel dissimilar refill friction stir spot welds. Int J Fatigue. 2016;92(1):78-86.
15. Cao JY, Wang M, Kong L, Zhao HX, Chai P. Microstructure, texture and mechanical properties during refill friction stir spot welding of 6061-T6 alloy. Mater Charact. 2017;128:54-62.

16. Tier MD, Rosendo TS, dos Santos JF, Huber N, Mazzaferro JA, Mazzaferro CP, Strohaecker TR. The influence of refill FSSW parameters on the microstructure and shear strength of 5042 aluminium welds. J Mater Process Technol. 2013;213:997-1005.

17. Ravichandran SP. Comparison of Refill Friction Stir Spot Welding Versus Riveting in Aircraft Applications. MSc Thesis. Wichita State University, Wichita, USA, 2019.

18. Li Z, Ji S, Ma Y, Chai P, Yue Y, Gao S. Fracture mechanism of refill friction stir spot-welded 2024-T4 aluminium alloy. Int J Adv Manuf Technol. 2016;86:1925-32.

19. Shen Z, Yang X, Zhang Z, Cui L, Li T. Microstructure and failure mechanisms of refill friction stir spot welded 7075-T6 aluminum alloy joints. Mater Des. 2013;44:476-86.

20. Dong H, Chen S, Song Y, Guo X, Zhang X, Sun Z. Refilled friction stir spot welding of aluminum alloy to galvanized steel sheets. Mater Des. 2016;94:457-66.

21. ISO 6892-1:2016. Metallic materials - Tensile testing - Part 1: Method of test at room temperature. International Organization for Standardization: Geneva, Switzerland, 2016.

22. Simufact Forming - Theory manual. Champaign: Computational Applications and System Integration Inc., 2016.

23. Park K. Development and Analysis of Ultrasonic Assisted Friction Stir Welding Process, PhD thesis. University of Michigan, Ann Arbor, USA, 2009.

24. Sallomi KN, Al-Sumaidae S. Numerical validation of temperature distribution in friction stir welded aluminum 7075-T651 plates using pseudo heat transfer model. Ann Chim Sci Mat. 2017;1-2:29-38.

25. Gerlich A, Yamamoto M, North TH. Local melting and tool slippage during friction stir spot welding of Al-alloys. J Mater Sci. 2008;43:2-11.

26. Gerlich A, Avramovic-Cingara G, North TH. Stir zone microstructure and strain rate during Al 7075-T6 friction stir spot welding. Metall Mater Trans A. 2006;37A:2773-866.

27. Suhuddin UFH, Fischer V, dos Santos JF. The thermal cycle during the dissimilar friction spot welding of aluminum and magnesium alloy. Scr Mater. 2013;68:87-90.

28. Gerlich A, Yamamoto M, North TH. Strain rates and grain growth in Al 5754 and Al 6061 friction stir spot welds. Metall Mater Trans A. 2007;38:1291-302.

29. Fratini L, Buffa G, Shivpuri R. Mechanical and metallurgical effects of in process cooling during friction stir welding of AA7075-T6 butt joints. Acta Mater. 2010;58:2056-67.

30. Zhao Y, Liu H, Yang T, Lin Z, Hu Y. Study of temperature and material flow during friction spot welding of 7B04-T74 aluminum alloy. Int J Adv Manuf Technol. 2016;88:1467-75.

31. Song M, Kovacevic R. Thermal modeling of friction stir welding in a moving coordinate system and its validation. Int J Mach Tools Manuf. 2003;43:605-15.

32. Al Zubaidy BMM. Material Interactions in a Novel Refill Friction Stir Spot Welding Approach to Joining Al-Al and Al-Mg Automotive Sheets. PhD Thesis, University of Manchester, Manchester, Great Britain, 2016.

33. Bai Y, Bai Q. Subsea Pipelines and Risers. Amsterdam, Holland: Elsevier Science; 2005.

34. Ji S, Wang Y, Li Z, Yue Y, Chai P. Effect of tool geometry on material flow behavior of refill friction stir spot welding. Trans Indian Inst Met. 2016;70(6):1417-30.

Publisher's Note Springer Nature remains neutral with regard to jurisdictional claims in published maps and institutional affiliations. 